Provided for non-commercial research and education use. Not for reproduction, distribution or commercial use.

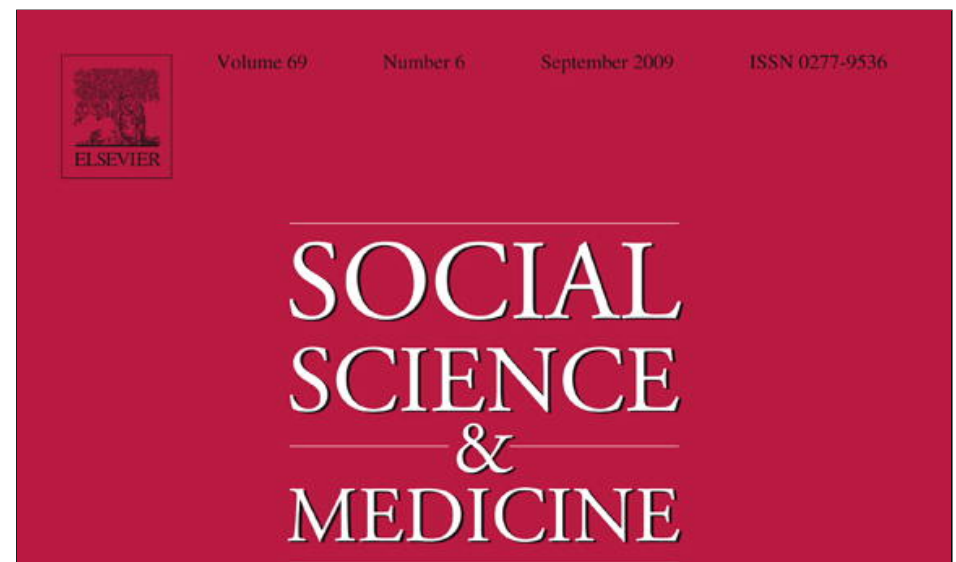

an international journal

Part Special Issue

Women, Mothers and HIV Care in Resource-Poor Settings

Guest Editors

Alice Desclaux, Philippe Msellati, Saskia Walentowitz

"We need to take into account the variations, interrelations and roles of women and men, in order to address the complexities of HIV care beyond gender dichotomies" (Desclaux, Msellati and Walentowitz, in this issue)

This article appeared in a journal published by Elsevier. The attached copy is furnished to the author for internal non-commercial research and education use, including for instruction at the authors institution and sharing with colleagues.

Other uses, including reproduction and distribution, or selling or licensing copies, or posting to personal, institutional or third party websites are prohibited.

In most cases authors are permitted to post their version of the article (e.g. in Word or Tex form) to their personal website or institutional repository. Authors requiring further information regarding Elsevier's archiving and manuscript policies are encouraged to visit:

http://www.elsevier.com/copyright 


\title{
Care and secrecy: Being a mother of children living with HIV in Burkina Faso
}

\author{
Fabienne Hejoaka ${ }^{a, b, *}$ \\ ${ }^{a}$ Centre d'Études Africaines - École des Hautes Études en Sciences Sociales, Paris, France \\ ${ }^{\mathrm{b}}$ Institut de Recherche pour le Développement, UMR 145 "VIH et maladies associées", UM1 Montpellier, France
}

\section{A R T I C L E I N F O}

\section{Article history:}

Available online 18 June 2009

\section{Keywords:}

Caregiving

Children

HIV/AIDS

Secrecy

Burkina Faso

Mother-child relationship

Mothers

\begin{abstract}
A B S T R A C $T$
Home care has become a central component of the response to the HIV/AIDS epidemic, displacing caregiving work onto women. While increasing interest has been paid to HIV/AIDS care with a focus on ailing adults and orphan foster care, the issue of caring for children living with HIV has received little attention in the social sciences. Based on ethnographic material gathered in Burkina Faso between November 2005 and December 2006, the aim of this paper was to gain understanding of women who mother and care for children living with HIV in resource-limited countries. The study involved participant observation in community-based organizations in Burkina Faso and semi-structured interviews with 20 women mothering HIV-positive children as well as 15 children infected with HIV, aged between 8 and 18 years. In daily care mothers face many great challenges, ranging from the routine of pill-taking to disturbing discussions with children asking questions about their health or treatment. The results also show how HIV/AIDSrelated stigma adds an additional layer to the burden of care, compelling mothers to deal with the tension between secrecy surrounding the disease and the openness required in providing care and receiving social support. As mothers live in fear of disclosure, they have to develop concealment strategies around children's treatment and the nature of the disease. Conversely, some mothers may share their secret with kin members, close relatives or their children to gain social support. As HIV/AIDS care is shaped by secrecy, these findings shed light on mothers' isolation in child care within a context of changing patterns of family bonds and lack of formal psychosocial support addressing child-related issues. Finally, women's engagement in child care invites us to look beyond the essentialist approach of women's vulnerability conveyed by international discourse to characterise the situation of women facing the HIV/AIDS impact.
\end{abstract}

(c) 2009 Elsevier Ltd. All rights reserved.

\section{Introduction}

The choice of the slogan "Women, Girls, HIV and AIDS" as theme of World AIDS Day in 2004 exemplifies the political recognition of the feminisation of the epidemic in low-resource countries (UNAIDS, 2004) as well as gender mainstreaming into AIDS policy and programming (Kleintjes, Prince, Cloete, \& Davids, 2005). Indeed, women account today for half of all the people living with HIV and nearly $60 \%$ of infection in sub-Saharan Africa (UNAIDS, 2008). HIV/ AIDS also strikes women by significantly increasing the burden of care they shoulder. As caregiving is a social role shaped by gender, women are generally seen as "natural" caregivers. In most societies, it is taken for granted that mothers, wives, grandmothers, aunts and sisters have to care for those in need - and particularly for children. Thus, like other kinds of care, HIV/AIDS care is primarily provided by women (Global Coalition on Women and AIDS, 2004) and the

\footnotetext{
* Corresponding author. Centre d'Études Africaines - École des Hautes Études en Sciences Sociales, Paris, France. Tel.: +33 (0)6 63450646 .

E-mail address: fabienne.hejoaka@ird.fr
}

elderly (Dayton \& Ainsworth, 2004; Nyambedha, Wandibba, \& Aagaard-Hansen, 2003; Ssengonzi, 2008).

Caregiving work refers to a range of services and activities including physical, medical, emotional, material and financial care. It operates at multiple levels such as health care system, community-based care programs and within domestic space. Within the home, the provision of care consists of domestic chores such as, in an African context: cooking, cleaning, carrying water and wood as well as taking care of children, the elderly, the disabled and sick people. In settings characterised by overburdened health care systems and shortages of health care workers (Van Damme, Kober, \& Kegels, 2008; WHO, 2006), home care has become a central component of the response to the AIDS epidemic, hence shifting the caregiving work onto women, who constitute the majority of informal and unpaid caregivers. In recent years, there has been an increasing amount of literature on AIDS-related care, with particular focus on care for ailing adults (Campbell, Nair, Maimane, \& Sibiya, 2008; Hamra, Ross, Karuri, Orrs, \& D’Agostino, 2005; Nkosi, Kipp, Laing, \& Mill, 2006) and foster care of orphaned children (Abebe \& Aase, 2007; Heymann, Earle, Rajaraman, Miller, \& Bogen, 2007; Hosegood 
et al., 2007; Meintjes \& Giese, 2006; Nyamukapa \& Gregson, 2005). So far, however, there has been little discussion in social science about caring for children living with HIV with the exception of a few studies (Brouwer, Lok, Wolffers, \& Sebagalls, 2000; O'Hare et al., 2005; Van Graan, Van der Walt, \& Watson, 2007).

As Richter (2008) pointed out during a plenary session at the International AIDS 2008 conference held in Mexico, children have remained "small issues" for policymakers and scholars. This relative invisibility may be explained by different factors. Firstly, HIV-positive children have remained a blind spot in the care and treatment of the HIV infection for two decades in low-resource countries (Desclaux, 1997; Domek, 2006; Elenga et al., 2006). Furthermore, despite recently scaled-up treatment access programs, a large majority of the 2.1 million children living with HIV/AIDS needing antiretroviral treatment do not have access to it (WHO, UNAIDS, \& UNICEF, 2008). Second, the complex reality of the impact of HIV/AIDS on both infected and affected children has often been undermined by the media as well as the academic emphasis on the so-called "orphan crisis" (Bicego, Rutstein, \& Johnson, 2003; Foster, Levine, \& Williamson, 2005; UNICEF, UNAIDS, \& WHO, 2007). Finally, children and childhood have not been recognized as a significant area of study by sociologists and anthropologists for a long time, making Hirschfeld (2002) ironically wonder in an eponymous article "Why don't anthropologists like children?". Even if in the last two or three decades the sociology and anthropology of childhood have gained increasing attention (James, Jenks, \& Prout, 1998; James \& Prout, 1997; Lallemand \& Le Moal, 1981; Mayall, 2002; Qvortrup, 1994), there is still a dearth of scholarship examining children as social actors and exploring the sense that children make of their worlds.

Understanding the daily AIDS care provided by women to HIVpositive children also requires consideration of the stigmatization surrounding HIV/AIDS. AIDS-related stigma has received a particular concern in the literature (Castro \& Farmer, 2005; Deacon, Stephney, \& Prosalendis, 2005; Mahajan et al., 2008; Parker \& Aggleton, 2003; Stein, 2003) and research has stressed how stigma may impede access to and provision of care (Simbayi et al., 2007; Turan, Miller, Bukusi, Sande, \& Cohen, 2008). HIV/AIDS-related stigma adds an additional layer to the burden of care, compelling mothers to deal with tension between the secrecy surrounding the disease and the openness required in providing care and receiving social support. Goffman's (1963) seminal work on social stigma provides an heuristic framework to explore care interactions shaped by secrecy. By distinguishing the discredited (those whose stigma is known) from the discreditable (those whose stigma can be hidden), Goffman highlighted how the problem of the discreditable is to manage information rather than the tensions generated during social contacts. It is in this context of the daily management of the secret that the care given by mothers to their infected children is embedded and must be understood.

The purpose of this paper was to gain understanding of women mothering and caring for children and adolescents living with HIV in resource-limited countries. Based on ethnographic material gathered in Burkina Faso, this article considers mothers' social experience of AIDS care and health work provided in a context of poverty, where the access of the populations to health care is precarious and inequitable (Nikièma, Haddad, \& Potvin, 2008; Ridde, 2008). As well, as stigma surrounds HIV/AIDS care, this article explores how tensions between disclosure and concealment of the disease shape caregiving work and may hinder care by limiting potential social support.

\section{Study location}

This study was conducted in Bobo-Dioulasso, the second largest city in Burkina Faso, with approximately 400,000 inhabitants in
2006. With an essentially rural (72.7\% of the population) and agricultural population, Burkina Faso holds the penultimate position (176th) in the ranking of the Human Development Index (UNPD, 2007). Since the declaration of the first case of AIDS in 1986, Burkina Faso has paid a high price for the epidemic. In recent years, the national prevalence rate among adults aged between 15 and 49 years has decreased from $7.1 \%$ in 1997 to $2 \%$ [1.5-2.5] in 2005 (UNAIDS, 2007). In Bobo-Dioulasso, the HIV prevalence rate was estimated at $4 \%$ among women and 3.2\% among men aged between 15 and 49 years in 2003. As far as stigma is concerned, Burkina Faso is today characterised by an ambivalent situation in which, despite the fact that HIV/AIDS tends to be more positively accepted, felt stigma is still significant among people living with HIV. Because they fear that their disease or children's may be disclosed, daily experience of treatment and care for children are placed under the seal of secrecy.

\section{Methods}

\section{Data collection}

The analysis presented on women's mothering HIV-positive children is part of a doctoral thesis in social anthropology examining the experience of the disease and its treatment among HIVinfected children and adolescents in Burkina Faso. The field study and the collection of data were carried out between November 2005 and December 2006 in Bobo-Dioulasso. The research was conducted in the framework of a partnership with the paediatric department of the Centre Hospitalier National Sanou Souro in Bobo-Dioulasso and two community care NGOs: 'Responsabilité Espoir Vie Solidarité' (Responsibility Hope Life Solidarity) and 'Action Espoir pour Demain' (Action Hope for Tomorrow) created in 1997 and 2003, respectively.

Interviews were conducted with 20 women mothering HIVpositive children and adolescents. Throughout this paper, the term "mother" will refer to both biological mothers and "substitute" mothers who take care of orphans. A total of fourteen biological mothers and seven "substitute" mothers were interviewed. "Substitute" mothers were aunts (4), grandmothers (2), and a cowife of a deceased mother in the case of polygamous marriage. Those mothers were aged between 17 and 72 years. Three of the mothers were married or in a couple, six of the mothers were widows, and five were "separated". Interviews were also conducted with 15 children and adolescents aged between 8 and 18 years. Twelve of the children were living with HIV and were informed of their status, while three were informed of their parents' or siblings' status. Qualitative methods adapted to research carried out with children were used (Christensen \& James, 2000; Fine \& Sandstrom, 1988; Punch, 2002). In particular, drawings were used as a support for interviews with children and adolescents. Ten health professionals (physicians, pharmacists, nurses, psychologists) as well as 12 members of various associations (counsellors, programme administrators, presidents) were also interviewed.

\section{Data analysis}

The qualitative methods employed for the data collection were participant observation, semi-structured interviews and focus groups. The recorded interviews were transcribed verbatim and translated into French in case of interviews conducted in dioula, a local language. The main themes considered in the course of the interviews included: the discovery of the disease; persons, informed or not informed, intervening in the care; the context of the daily administration of medication; the problems encountered and the solutions provided; the notification of the disease to a third 
party or to a child. Data were coded into organising themes in an iterative process (Bazeley, 2007) and analyzed using QSR NVIVO software (version 7).

\section{Ethical considerations}

Research was conducted in compliance with an ethical protocol approved by the National Health Research Ethics Committee in Burkina Faso in December 2005. The mothers were contacted through the intermediary of community counsellors and were informed of the purposes of the research. Parental informed consents - written or verbal for illiterate people - were obtained for interviews. With parental authorization, children older than 8 years who were informed of their status or that of a family member were asked to participate in the research. The study was presented as intending to obtain participants' experience about their daily life, the disease and the treatment. They were informed that they were free to refuse or to stop participating at any time. Children interviewed were used to seeing the study's author, who regularly came to visit the associations and take part in some children's activities (plays, drawings, and school support) in the 6 months preceding the study. All data were anonymized and pseudonyms were used.

\section{Results}

\section{Everyday life constraints in child care and treatment}

Notifying others of a child's illness involves a re-organization of daily life and an evolution of social relations between the mother and the infected child. The necessity of routinely taking medicines is one of the most common constraints faced by women mothering children with HIV. Because the effectiveness of antiretroviral drugs is dependent on the regularity of the treatment, precise hours are specified to ensure patients' adherence. The times for medication have thus become an essential component of physicians' recommendations. However, faced with these imperative prescriptions, the mothers often perceive their respecting of the timings as a condition of the effectiveness of the drug, which creates anxietyprovoking situations. For many of them, a short delay in the prescribed time may eliminate the effectiveness of the treatment, as this mother explained:

When I'm a half hour late with my daughter's medicines, my body begins to tremble. I'm afraid and get excited. I touch the child to see if she is hot and ask her if she feels good. (Mother of a 9-year-old girl)

The concern around scrupulously respecting the timings makes it necessary to organize the day according to the medication times and the nutritional constraints that may sometimes be connected therewith. For some drugs, this means taking pills $2 \mathrm{~h}$ after eating or $1 \mathrm{~h}$ before eating. Because of the standardisation of prescriptions and a lack of family approach, mothers themselves must generally adapt to the times for medication despite timings that may not fit in with their daily or occasional constraints. Furthermore, because of the newness of programmes of access to antiretroviral and the lack of adequately trained human resources providing individual follow-up integrating patients' constraints, some women had to manage different times of pills-taking in themselves and their children. A typical scenario is represented through the following case:

I take two pills of cotri ['cotri' is a diminutive of co-trimoxazole, a combination of antibiotics commonly used to prevent or treat some opportunistic infections related to HIV] in the morning at 7 and in the evening one pill of Triomune ${ }^{\circledR}$. [Triomune is a triple drug combination commonly used to treat HIV] [...] My daughter takes her pills at 6 o'clock. [...] My doctor told me to take my medicines at 7 but her doctor said she has to take them at 6 am and $6 \mathrm{pm}$. So, I do what the doctors have recommended. (Mother of an 11-year-old girl)

The re-organization of the family economy is determined by frequently underestimated socio-economic constraints, as a health professional observed:

In the beginning, thinking about the adherence to treatment, one forgot that not all women are at home at six in the evening. Some of them have constraints and are not always there to give the child its medication. (Health professional)

The family status of the mothers directly influences their ability to adjust to the constraints imposed by the daily management of the disease. Widows or women who are heads of the family and who must ensure the income of the household through outside work thus have less room to manoeuvre. Most of these women have an informal commercial activity (sale of fruits and vegetables, undergarments and beauty products, preparation of meals and sale of beverages) that imposes time constraints incompatible with the children's medication schedule. Some are thus forced to leave the market before closing time or delegate the dispensing of the medicine to a member of the family who has not been wholly informed of the situation. This can prove to be problematical for the regularity of the treatments. The persons in charge of dispensing them during the absence of the primary caregiver might be unaware of the importance of and the reasons for respecting the scheduling or nutritional constraints. When they were not able to adapt their times, some mothers abandoned their jobs so as to care for the child, which has a socio-economic impact on the life of the family unit.

The professional and daily care constraints described were made more ponderous through the mobility problems women face. In an urban context characterised by the absence of public transport, women who were unable to pay a taxi or purchase a motorbike or a bicycle were forced to move about for the most part on foot. In addition to the distance they must travel to get to work, they have to work for hours to get to the hospital or to an association. Grandmothers and HIV-infected women are already weakened by the disease stressed the fatigue caused by transportation matters in ensuring children's follow-up, as this mother commented:

Each Friday, I have to go to the hospital to weigh in the baby. On Thursday, it's my daughter. But, it's a long way from where we live. Most of the time, I have to walk. When I have money, I take a taxi, but it's seldom. When I have no money, I have to walk to the hospital. Some days I don't feel good. It's why, sometimes, I don't take them to the hospital. Last month, I was waiting for the results of the baby's test. I was afraid of the results, because two of my children are already infected and very tired. One day, on the way to hospital, I was exhausted... I couldn't move forward. I sat down and cried. (Mother of an 8-year-old girl)

A grandmother explained how every week her grandson aged 8 years walks $4 \mathrm{~km}$ to the hospital by himself to get his medicines:

Two months ago, I was sick and was not able to oversee his pillstaking. He missed some intakes. They were not happy at the hospital and told me that we have to come every week to get his treatment. But, I often don't feel good and now he goes alone to the hospital every Thursday... When I see him go away to the hospital, this sickens me... (Grandmother of an 8-year-old boy)

Some mothers also complained of a constant concern about the possibilities of the transmission of the disease in the domestic 
space by exposure to blood through the common use of certain things; thus, toothbrushes, flat razor blades used to cut toenails and needles used to fasten the hair become objects for personal use. Despite their knowledge of the modes of transmission, some mothers mentioned practices that restrict even non-contaminating bodily contact with their child. The fear of contagion is expressed through a reluctance to kiss the baby or to use the same spoon. A study conducted in 2004 among 344 North American parents presented similar results (Zimet et al., 2005). For example, although responding in the negative when asked about the possibility of contamination in those ways, this mother of two HIV-positive children aged of 8 and 14 years, was afraid of having infected her 18-month-old son:

Sometimes my son comes and puts his mouth on mine. I told him not to do that. I also told to his sister not to accept that he put his mouth on hers. And I don't want her to kiss him. Last time, when they shaved him, I told her to be very careful, mostly when they have wounds. Because he is little, he is weak. When I think of it, I can't kiss him as I did with my other children when I didn't know I had HIV. I could touch and kiss them... But with my last child, I often look at my hands to see if I have no wounds before touching him. (Mother of an 18-month-old boy)

Another mother explained that she might react violently because of this fear of contagion:

Because I'm infected, I'm afraid of infecting my children. The one who goes to school, I'm afraid because when I eat, if I let my spoon, he takes it. I'm afraid... I hit him, because I don't want him to do that. (Mother of an 11-year-old boy)

The role of women mothering HIV-positive children is not limited to domestic care, but is also a matter of "health work" when the children have episodes of illness. Whether at home or in the hospital, the mothers play a helper's role in care, the function of the nursing staff being limited to the dispensation of medication and the execution of medical acts and excluding the "care work" which arises with the illness. Mothers provide the "health care work" through different nursing tasks such as procuring and administering the medicine, helping a malnourished child to eat, washing for the sake of daily hygiene but also in the case of repeated vomiting and diarrhoea, or ensuring the continuity of the drip. Moreover, when the child continued to be sick despite antiretroviral treatment - no regaining of weight, appearance of opportunistic infections or biological indicators not improving the mothers' work could be seen as suspect in terms of "their good administration of the treatments". Those situations were all the more difficult to manage and to emotionally endure when the mothers observed improvements in the health of other children at hospital services or community-based associations. Finally, when the child entered the advanced stage of the illness, the mothers provided palliative care in the absence of adequate institutional means at the level of the hospital.

\section{Fears of disclosure and concealment strategies}

\section{Fear of disclosure with adults}

In the context of HIV infection, caregiving work required by dayto-day management of the disease is shaped by secrecy. This implies on their part a "manipulation of information" (Goffman, 1963) and the development of concealment strategies to dissimulate child's treatment and the nature of the disease. Mothers emphasized the need to conceal the treatments from uninformed members:

I put the medicines in a bag and put them away in the wardrobe in my room. When it's time to take the pills, I call my daughter and I give her the medicine on the sly in my room (Mother of 11year-old girl)

Another mother described how she burnt the packaging of the medicines to prevent being found by somebody:

There are packaging boxes with the medicines. I don't want people to find them. We often see ARV on TV and they may guess ... There is a well in your yard but it's not yet used. So, I throw them into the well and burn everything (Grandmother of an 8-year-old girl)

The major challenge faced by mothers is to manage the family circle. Family members - especially "old women" - generally assume a central role in domestic health care (Bezner Kerr, Dakishoni, Shumba, Msachi, \& Chirwa, 2007; Bonnet \& Pourchez, 2007; Cresson \& Falquet, 1996). However, because of stigma surrounding HIV/AIDS, the mothers limit access so as to keep the disease secret. For example, in face-to-face situations, they must justify artificial feeding of the child in a context in which $98 \%$ of the children are breastfed from birth for an average of 22 months (ISND \& ORC Macro, 2004). The following is a case in point:

When I gave birth to my son, my old uncle's wife told she would came to take care of the baby and that she would leave when I feel better. She has washed the baby for several days. When his belly button fell, she wanted to give him some water. I told her that the doctor had told me not to give water to the baby. She answered she had 13 children who were given water. None of them died, so why something should happen to mine, if he drinks water? On contrary, water gives weight and strength. She was angry... Now, every time she sees me, it's only discussions and questions about the baby. (Mother of a 4-month-old boy)

In the case of food constraints related to treatment schedule, mothers were also obliged to explain why their child cannot eat like other children. One mother stated:

When he has to take his pills, I forbid him to eat. He takes his medicine at $6 \mathrm{pm}$. But when his grandfather is at home, he likes to give him money to buy something to eat. I have to say no to the grandfather... When people see that, they say: "What's that! Your child needs to eat!" If you are not here, they can call him and give him something to eat or ask him why he can't eat. It's not easy... (Mother of a 12-year-old boy)

Mothers' concealment strategies were particularly difficult to maintain outside the domestic space. Sometimes, children might be fostered to a family member because of the mother's illness, for family obligations such as bereavement or a professional journey. Family members also cared for children in usual circumstances like summer holidays or visits to family members. A mother reported how she was put in an awkward position because of his brother's suspicion:

My old brother may know. My daughter went to stay by him during last summer holidays. Because of her treatment she has a specific hour to eat. She mustn't eat anything two hours before taking her medicines. If she takes her medicines at $6 \mathrm{pm}$ she has to wait until $8 \mathrm{pm}$ before eating. I told him that she has to take medicines, but I don't explain why. He may have guessed something. He told to my older daughter that we might hide something... He decided that if it's not $8 \mathrm{pm}$, none of the children of the house can eat. I know that next time we will meet, he will ask me for some explanations! (Mother of a 9-year-old girl)

Finally, mothers not only face difficulties concealing the disease and treatment. They also have to justify regular visits to hospital. Beyond monthly visits, children's clinical follow-up may occur 
every week when children are underweight and need to be regularly weighed, or even daily, when they require nutritional support in a recovery program.

\section{Fear of disclosure with children}

The mothers were not only confronted with adults' questions but also with children's. In fact, as they became accustomed to the treatment, children tended to raise disconcerting questions. A common question asked by many children is, "Mummy, what illness do I have?" Facing with such embarrassing inquiries, mothers used being underweight, weakness, sickly condition and malaria (which is endemic in the country) as alibis. A comment from an aunt illustrated a frequent reply among mothers:

When the child asks me questions, I get upset. I don't know what to say. I tell her that it's nothing, it's malaria and to go away and play. (Aunt of a 12-year-old girl)

Faced with children's inquisitive questions about their illness or their "good state of health which should not require taking drugs every day", mothers' helplessness could be expressed through harsh responses - for themselves as much as for the children referring to fatality. Examples are presented through the following cases:

When my daughter doesn't want to take her drugs, I tell her to take them or she will die. (Mother of an 8-year-old girl)

I tell her to take her medicines otherwise she will die. So, now she doesn't play with her treatment. If time of pills-taking is arrived, she comes back home. If her older sister is not there, she is becoming to cry... (Grandmother of a 9-year-old girl)

The use of "death" to persuade children to take their pills was confirmed by the statement of an 8-year-old girl recently informed of her status.

Mummy tells me to take my pills, otherwise I will die and to not tell anybody [...]. If mummy tells me not to tell anybody, it's because it's AIDS. (Marie, 8-year-old girl)

One of the most common barriers to disclosing HIV to children was adults' perceptions of children's inability to maintain secrecy. Parents, but also health and community workers, considered that children were not able to keep their HIV status a secret and that they might reveal it if they were informed. They also underestimated children's knowledge and understanding of HIV/AIDS and the stigmatization associated with it. Therefore, when children who were supposed not to be aware of their status asked questions referring to HIV/AIDS, parents were particularly upset, as mothers explained:

She is still young. I believed that she didn't understand the disease. One day we watched a play on AIDS at the association. Back home, I asked her if she knew what AIDS was. She replied me that it was diarrhoea. Because the counsellors of the association advise us to inform the children, I talked again with her. This day, while I was giving her the pills, I asked her: "Do you know what kind a disease those medicines cure?" She told me that she knew and answered: "It's medicine for AIDS"... She had looked at my face and added that it was also a medicine that cures headache... (Mother of an 8-year-old girl)

My daughter asked me what illness she had. I told her it was malaria, and she answered that that wasn't true. A few days later, we were at prayer group; she prayed aloud that all those in the world with AIDS would be cured! (Mother of a 9-year-old girl)

The difficulties faced by mothers in communicating with children raise the tricky issue of HIV disclosure to children. As an increasing number of children are growing up with HIV because of HAART (highly active antiretroviral therapy) roll-out, HIV disclosure to children has become one of the most challenging issues faced by mothers. However, as health and community workers are ill-trained and lack guidance on child-related issues, the decision of whether and how to disclosure HIV status lies mostly with mothers.

\section{Sharing the secret to facilitate child care}

The emotional and material burden involved in the daily management of the disease and long-term treatment led some mothers to share their secret with close relatives or a person likely to support them in the care of the child. In a context in which the sharing of the status with those around is restricted, disclosure to a third person was generally motivated by the well-being of the child so as to ensure the continuity of treatment and follow-up. The husband, another member of the family or children's may be let in on the secret.

Some mothers were divorced or had been "abandoned" by the father of the child, mostly when the child was a baby. Whereas none of them had previously informed their former husband or partner of their status, they chose to reveal the status of the child and at the same time their own - to ensure the continuity of the child's care. One mother commented:

My husband left me three years ago to go off with a younger woman. At that time, I was often sick. When I got the results of my test, I didn't want to tell him. Now that our girl is seven years old, he wants her to live with him. I told him she had AIDS and that she had to take drugs every day. Because she has to be regularly followed up at the hospital and given drugs every day, he let her with me. (Mother of a 7-year-old girl)

Disclosure also involved the child's brothers and sisters, in some cases from the age of 9 years. This generally occurred in the case of single parent families headed by mothers. In a context of social isolation and emotional shock caused by the discovery of the partner's disease or death, children are often the only possible intermediaries, as described this mother of four, two of them 4 years old and infected and under treatment:

Since I felt sick, the doctor knew that only my mother took care of me, anybody else. One day, he asked me where my husband was. I answered him that things went wrong and he had left. Until present, his family hasn't supported me... They even don't come to see me. The doctor advised me to inform my old daughter [13-year-old] to help me to take care of the twins. One day, I felt sick and my mother was not there. I was not able to go to the hospital to get the children's medicines. At that time, I have informed my daughter. Now she takes care of the twins and gives them their treatment. (Mother of 4-year-old twin boys, 7-year-old boy, and 13-year-old girl)

Children living with HIV actually played an important role in their treatment. They might take their medicines themselves when they knew how to do so and had access to the storage place. A number of the mothers interviewed also explained that children living with HIV frequently remind them when it is time to take the medicines, whether they had been informed that they were HIV positive or not. Children were often essential in remembering to take medicines at the right time, using a variety of mnemonic techniques (e.g., use of a watch, a mobile phone alarm, or among Muslims adjustment of the timings to those of the prayers). In the domestic space, alone with the parent, the children might openly talk to remind the parent of the hour. A mother commented: 
When it's time to take his medicines, my son comes and tells me: "Mummy it's time to take my pills." (Mother of a 14-year-old boy)

Acting as adults, children also developed strategies to conceal the medicines and the disease. For instance, in the presence of other persons, children used diverse strategies aiming to notify the parent discreetly. For example, the children could make certain signs, such as putting the hand on the mouth and tapping on the lips to denote taking medicine, making a slight movement of the head or raising the eyebrows while looking towards the house or storage place of the medicines. They could also whisper in their mother's ear: "it's time".

When it's time to take her medicines, if people are at home, she comes to me and makes sign. She raises her hand to mouth and taps on her lips to signify that she has to swallow her pills. I told her that if someone is there, she must not come and tell me "Mummy, come and give my medicine." She well respects this. (Aunt of a 12-year-old girl)

If it's 6 am and people are at home she comes up to me and says:

"Mummy, the ox is passing. Every morning an ox goes past our house at $6 \mathrm{am}$. (Mother of an 8-year-old girl)

Children's concealment strategies were dictated by parents' prescriptions to hide pills and "not to tell to anybody". However, even without such parental prescriptions, children scrupulously kept the secret because they were aware of the secret dimension surrounding the disease. Children feared especially that other children might not play with them if they knew their parents' or their own status.

If I told the others that I have AIDS, they wouldn't want anymore to play with me. (Fatoumata, 12-year-old girl)

I don't like hearing people who talk badly on people with AIDS. I want to tell them it's wrong, but if I do that, they may tell that I defend them because I also have AIDS. (Mamadou, 11-year-old boy)

If they know that, I will stay alone... they would be afraid that I may infect them. (Eric, 11-year-old boy)

\section{Discussion}

This qualitative study describes the caregiving work provided by women mothering children and adolescents living with HIV in Burkina Faso. Far beyond the essentialist approach of women's vulnerability largely conveyed by contemporary international discourse, our results highlight women's agency in coping with both their child's illness and the related home care. In daily care mothers face many great challenges ranging from the routine of pills-taking to disturbing face-to-faces with children asking for questions about their health or their treatment. Furthermore, when they take care of critically ill children, mothers become "substitute" health care workers, sometimes providing palliative care. In such a context, taking daily care of children in a long-term perspective may cause "fatigue" in mothers (Thomas, 2006).

The findings draw attention to mothers' isolation in children health care and treatment. Mothers are isolated as caregivers because they limit potential social support so as to keep the disease secret. Whether some mothers disclose children's status to gain support from relatives, others do not and must develop strategies to hide the disease and the child's treatments. Many of our findings regarding social constraints hindering HIV treatment and care are similar to those of other studies describing fear of disclosure (Kipp, 2007; Makoae \& Jubber, 2008; Ndinda, Chimbwete, McGrath, Pool, \& Group, 2007) and how stigma may hinder care (Alonzo \&
Reynolds, 1995; Hamra, Ross, Orrs, \& D’Agostino, 2006; Radstake, 2000).

Beyond stigma, mothers' isolation in caring for children also needs to be analyzed in the context of weakening family bonds observable in Burkina Faso and widely described in other African contexts (Madhavan, 2004; Nyambedha et al., 2003). Recent studies have shed light on increasing men's involvement in caregiving (Kipp, Tindyebwa, Karamagi, \& Rubaale, 2006; Montgomery, Hosegood, Busza, \& Timæus, 2006), but these findings also share their findings with other recent studies showing that women are confronted with a growing isolation in the foster care of orphans (see for example Nyamukapa \& Gregson, 2005 in Zimbabwe and Upton, 2003 in Botswana).

By suggesting an increasing role of maternal kin, mother's care burden challenges the idealised vision of the extended family and raises the question of who in the kinship network would and could take care of the children, particularly when the child is HIV positive.

These findings also suggest changing patterns in social relations between the mother and their infected child. The announcement of the child's illness marks a "biographical disruption" (Bury, 1982) largely described in other contexts of chronic illness. This involves a re-organization of daily life and creates singular social relations between mothers and children. This may take the form of a "therapeutic complicity" in which children are involved, more or less openly, in the "work" of managing their illness. Far from being "passive patients", dependent on a third person for their treatment and care, children thus appear to be effective social support providers for their own in treatment and care. Children's engagement in treatment has also been described in a recent study conducted on the adherence to antiretroviral treatment in Botswana, Tanzania and Uganda (Hardon et al., 2006).

Mothers' isolation is worsened by the lack of effective formal psychosocial support targeting children as Wong, Macleod, Gilks, Higgins, and Crowley (2006) have underscored in their analysis of international policies on voluntary counselling and universal access to treatments for children. The issue of HIV disclosure to children particularly exemplifies this institutional gap. While, in western countries, a large body of literature has attempted to explain the complexity of HIV disclosure to children and the imperative need for formal supports (Hawk, 2007; Tompkins, 2007; Wiener, Mellins, Marhefka, \& Battles, 2007), the rare studies conducted in lowresource countries show a lack of assessed interventions and of institutional support (Bikaako-Kajura et al., 2006; Kouyoumdjian, Meyers, \& Mtshizana, 2005; Rwemisisi, Wolff, Coutinho, Grosskurth, \& Whitworth, 2008; Vaz et al., 2008). In such a context, HIV disclosure to children in low-resource countries is still missing from the AIDS policy agenda (Hejoaka, 2008) and consequently overloads women's burden of child care and emotional work.

Finally, mothers' isolation challenges AIDS policies and programs, which tend to undervalue the central role of caregivers and fail to understand their specific social support needs. In addressing family and community-based care, further research should integrate individual approaches in order to emphasise the experience of both caregivers and children in a context where care is shaped by secrecy. The feminist ethic of care (Gilligan, 1982; Paperman \& Laugier, 2004; Tronto, 1993) provides a challenging framework through which to examine the role of informal caregivers and care recipients. By placing relationships at the heart of care, the ethic of care may increase our understanding of the complex role of gender and age in the process of AIDS care.

\section{Acknowledgements}

Our heartfelt thanks are due to the children, adolescents, parents, health and community workers who co-operated and 
participated in the research process. We also wish to thank our supervisors Doris Bonnet (IRD/EHESS - UMR 196) and Dr Philippe Msellati (IRD - UMR 145), as well as Abdramane Berthe and Issika Bamba (SHADEI - Burkina Faso) for their support during fieldwork. We also extend thanks to the community-based organizations AED and REVS+ as well as Pr Aboubacar Nacro and the staff of the pediatrics department in the Souro Sanou University Hospital of Bobo-Dioulasso in Burkina Faso for their collaboration. This study has benefited from doctoral grants of the French National Agency for Research on HIV/AIDS (ANRS) and SIDACTION. We are also very grateful to the critical and constructive comments of the anonymous reviewers.

\section{References}

Abebe, T., \& Aase, A. (2007). Children, AIDS and the politics of orphan care in Ethiopia: the extended family revisited. Social Science \& Medicine, 64(10), 2058-2069.

Alonzo, A. A., \& Reynolds, N. R. (1995). Stigma, HIV and AIDS: an exploration and elaboration of a stigma trajectory. Social Science E Medicine, 41(3), 303-315.

Bazeley, P. (2007). Qualitative data analysis with NVIVO. London: Sage.

Bezner Kerr, R., Dakishoni, L., Shumba, L., Msachi, R., \& Chirwa, M. (2007). "We Grandmothers Know Plenty": breastfeeding, complementary feeding and the multifaceted role of grandmothers in Malawi. Social Science E Medicine.

Bicego, G., Rutstein, S., \& Johnson, K. (2003). Dimensions of the emerging orphan crisis in sub-Saharan Africa. Social Science E Medicine, 56(6), 1235-1247.

Bikaako-Kajura, W., Luyirika, E., Purcell, D. W., Downing, J., Kaharuza, F., Mermin, J., et al. (2006). Disclosure of HIV status and adherence to daily drug regimens among HIV-infected children in Uganda. AIDS and Behavior, 10(4 Suppl.), S85-S93.

Bonnet, D., \& Pourchez, L. (2007). Du Soin au Rite de l'Enfance. Paris: Erès; IRD.

Brouwer, C. N., Lok, C. L., Wolffers, I., \& Sebagalls, S. (2000). Psychosocial and economic aspects of HIV/AIDS and counselling of caretakers of HIV-infected children in Uganda. AIDS Care, 12(5), 535-540.

Bury, M. (1982). Chronic illness as biographical disruption. Sociology of Health and Illness, 4(2), 167-182.

Campbell, C., Nair, Y., Maimane, S., \& Sibiya, Z. (2008). Supporting people with AIDS and their carers in rural South Africa: possibilities and challenges. Health and Place, 14(3), 507-518.

Castro, A., \& Farmer, P. (2005). Understanding and addressing AIDS-related stigma: from anthropological theory to clinical practice in Haiti. American Journal of Public Health, 95, 53-59.

Christensen, P. M., \& James, A. (2000). Research with children. New York: Falmer Press.

Cresson, G., \& Falquet, J. (1996). Le travail domestique de santé, analyse sociologique. Nouvelles questions féministes, 17(4), 107-111.

Dayton, J., \& Ainsworth, M. (2004). The elderly and AIDS: coping with the impact of adult death in Tanzania. Social Science \& Medicine, 59(10), 2161-2172.

Deacon, H., Stephney, I., \& Prosalendis, S. (2005). Understanding HIV/AIDS stigma: A theoretical and methodological analysis. HSRC Press.

Desclaux, A. (1997). L'épidémie invisible: Anthropologie d'un système médical à l'épreuve du SIDA chez l'enfant à Bobo Dioulasso, Burkina Faso. Lille: Presses universitaires du Septentrion.

Domek, G. J. (2006). Social consequences of antiretroviral therapy: preparing for the unexpected futures of HIV-positive children. The Lancet, 367(9519), 1367-1369.

Elenga, N., Fassinou, P., Dossou, R., Dago, A., Akribi, H., \& Msellati, P. (2006). La tache aveugle de l'infection par le VIH en Afrique: la prise en d'un programme pilote, le "Programme enfant Yopougon". In Academia. (Ed.), Santé de la reproduction et fécondité dans les pays du Sud. Nouveaux contextes et nouveaux comportements (pp. 332-359). Bruxelles: Academia.

Fine, G. A., \& Sandstrom, K. (1988). Knowing children: Participant observation with children. Newbury Park, CA: Sage.

Foster, G., Levine, C., \& Williamson, J. (2005). A generation at risk: The global impact of HIV/AIDS on orphans and vulnerable children. Cambridge University Press.

Gilligan, C. (1982). In a different voice. Cambridge, MA: Harvard University Press.

Global Coalition on Women and AIDS. (2004). Background brief series: Care, women and AIDS. Available from: http://data.unaids.org/GCWA/GCWA_BG Care_en.pdf. Accessed 6.10.05.

Goffman, E. (1963). Stigma: Notes on the management of spoiled identity (1986 ed.). Simon and Schuster.

Hamra, M., Ross, M. W., Karuri, K., Orrs, M., \& D’Agostino, A. (2005). The relationship between expressed HIV/AIDS-related stigma and beliefs and knowledge about care and support of people living with AIDS in families caring for HIV-infected children in Kenya. AIDS Care, 17(7), 911-922.

Hamra, M., Ross, M. W., Orrs, M., \& D'Agostino, A. (2006). Relationship between expressed HIV/AIDS-related stigma and HIV-beliefs/knowledge and behaviour in families of HIV infected children in Kenya. Tropical Medicine $\mathcal{E}$ International Health, 11(4), 513-527.
Hardon, A., Davey, S., Gerrits, T., Hodgkin, C., Irunde, H., Kgatlwane, J., et al. (2006). From access to adherence: The challenges of antiretroviral treatment. Studies from Botswana, Tanzania and Uganda. Genève: World Health Organisation.

Hawk, S. T. (2007). Disclosures of maternal HIV infection to seronegative children: a literature review. Journal of Social and Personal Relationships, 24(5), 657-673.

Hejoaka, F. (4 August 2008). HIV Disclosure to children in low-resource countries: A Forgotten issue on the international AIDS policy agenda. Oral Abstract Session "Children and Youth Facing HIV/AIDS". Paper presented at the AIDS 2008-XVII International AIDS Conference, Mexico.

Heymann, J., Earle, A., Rajaraman, D., Miller, C., \& Bogen, K. (2007). Extended family caring for children orphaned by AIDS: balancing essential work and caregiving in a high HIV prevalence nations. AIDS Care, 19(3), 337-345.

Hirschfeld, L. A. (2002). Why don't anthropologists like children? American Anthropologist, 104(2), 611-627.

Hosegood, V., Floyd, S., Marston, M., Hill, C., McGrath, N., Isingo, R., et al. (2007). The effects of high HIV prevalence on orphanhood and living arrangements of children in Malawi, Tanzania, and South Africa. Population Studies - A Journal of Demography, 61(3), 327-336.

Institut National de la Statistique et de la Démographie \& ORC Macro(INSD \& ORC Macro). (2004). Enquête démographique et santé 2003. Calverton, Maryland, USA: ISND \& ORC Macro.

James, A., Jenks, C., \& Prout, A. (1998). Theorizing childhood. Cambridge: Polity Press. p. 247.

James, A., \& Prout, A. (1997). Constructing and reconstructing childhood: Contemporary issues in the sociological study of childhood. Falmer Pr.

Kipp, W. (2007). Family caregivers in rural Uganda: the hidden reality. Health Care for Women International, 28(10), 856-871.

Kipp, W., Tindyebwa, D., Karamagi, E., \& Rubaale, T. (2006). Family caregiving to AIDS patients: the role of gender in caregiver burden in Uganda. Journal of International Women's Studies, 7, 1.

Kleintjes, S., Prince, B., Cloete, A., \& Davids, A. (Eds.). (2005). Gender mainstreaming in HIV/AIDS. Seminar proceedings, Vol. 165. Cape-Town: HSCR Press.

Kouyoumdjian, F. G., Meyers, T., \& Mtshizana, S. (2005). Barriers to disclosure to children with HIV. Journal of Tropical Pediatrics, 51(5), 285-287.

Lallemand, S., \& Le Moal, G. (1981). Un petit sujet. Journal de la Société des Africanistes Paris, 51(1-2), 5-21.

Madhavan, S. (2004). Fosterage patterns in the age of AIDS: continuity and change. Social Science E Medicine, 58(7), 1443-1454.

Mahajan, A. P., Sayles, J. N., Patel, V. A., Remien, R. H., Sawires, S. R., Ortiz, D. J., et al. (2008). Stigma in the HIV/AIDS epidemic: a review of the literature and recommendations for the way forward. AIDS, 22, S57.

Makoae, M. G., \& Jubber, K. (2008). Confidentiality or continuity? Family caregivers' experiences with care for HIV/AIDS patients in home-based care in Lesotho. Journal of Social Aspects of HIV/AIDS, 5(1), 36-46.

Mayall, B. (2002). Towards a sociology for childhood: Thinking from children's lives. Philadelphia, PA: Open University Press.

Meintjes, H., \& Giese, S. (2006). Spinning the epidemic: the making of mythologies of orphanhood in the context of AIDS. Childhood, 13(3), 407-430.

Montgomery, C. M., Hosegood, V., Busza, J., \& Timæus, I. M. (2006). Men's involvement in the South African family: engendering change in the AIDS era. Social Science \& Medicine, 62(10), 2411-2419.

Ndinda, C., Chimbwete, C., McGrath, N., Pool, R., \& Group, M. (2007). Community attitudes towards individuals living with HIV in rural KwaZulu-Natal, South Africa. AIDS Care, 19(1), 92-101.

Nikièma, B., Haddad, S., \& Potvin, L. (2008). Women bargaining to seek healthcare: norms, domestic practices, and implications in rural Burkina Faso. World Development, 36(4), 608-624.

Nkosi, T. M., Kipp, W., Laing, L., \& Mill, J. (2006). Family caregiving for AIDS patients in the Democratic Republic of Congo. Healthcare Quarterly, 9(3), 94-101.

Nyambedha, E. O., Wandibba, S., \& Aagaard-Hansen, J. (2003). "Retirement lost" the new role of the elderly as caretakers for orphans in Western Kenya. Journal of Cross-Cultural Gerontology, 18(1), 33-52.

Nyamukapa, C., \& Gregson, S. (2005). Extended family's and women's roles in safeguarding orphans' education in AIDS-afflicted rural Zimbabwe. Social Science E Medicine, 60(10), 2155-2167.

O'Hare, B. A. M., Venables, J., Nalubeg, J. F., Nakakeeto, M., Kibirige, M., \& Southall, D. P. (2005). Home-based care for orphaned children infected with HIV/AIDS in Uganda. AIDS Care, 17(4), 443-450.

Paperman, P., \& Laugier, S. (Eds.). (2004). Le souci des autres. Ethique et politique du Care. Paris: EHESS

Parker, R., \& Aggleton, P. (2003). HIV and AIDS-related stigma and discrimination: a conceptual framework and implications for action. Social Science E Medicine, $57(1), 13-24$.

Punch, S. (2002). Research with children: the same or different from research with adults? Childhood, 9(3), 321.

Qvortrup, J. (1994). Childhood matters: an introduction. Childhood Matters: Social Theory, Practice and Politics 1-23.

Radstake, M. (2000). Secrecy and ambiguity: Home care for people living with HIV/ AIDS in Ghana. Leiden: African Studies Centre.

Richter, L. (2008). No small issue: Children and families. Universal Action Now. Plenary Presentation at the XVII International AIDS Conference "Universal Action Now", Mexico City, Mexico, 6 August 2008, Online Outreach Paper 3, Bernard van Leer Foundation, The Hague, The Netherlands. Available from http://www. bernardvanleer.org/publication_store/publication_store_publications/no_ small_issue_children_and_families_universal_action_now_/file. 
Ridde, V. (2008). "The problem of the worst-off is dealt with after all other issues": the equity and health policy implementation gap in Burkina Faso. Social Science E Medicine, 66(6), 1368-1378.

Rwemisisi, J., Wolff, B., Coutinho, A., Grosskurth, H., \& Whitworth, J. (2008). 'What if they ask how I got it?' Dilemmas of disclosing parental HIV status and testing children for HIV in Uganda. Health Policy and Planning, 23(1), 36-42.

Simbayi, L. C., Kalichman, S., Strebel, A., Cloete, A., Henda, N., \& Mqeketo, A. (2007). Internalized stigma, discrimination, and depression among men and women living with HIV/AIDS in Cape Town, South Africa. Social Science E Medicine, 64(9), 1823-1831.

Ssengonzi, R. (2008). The impact of HIV/AIDS on the living arrangements and wellbeing of elderly caregivers in rural Uganda. AIDS Care, 21(3), 309-314.

Stein, J. (2003). HIV/AIDS stigma: the latest dirty secret. African Journal of AIDS Research, 2(2), 95-101.

Thomas, F. (2006). Stigma, fatigue and social breakdown: exploring the impacts of HIV/AIDS on patient and carer well-being in the Caprivi Region, Namibia. Social Science \& Medicine, 63(12), 3174-3187.

Tompkins, T. (2007). Disclosure of maternal HIV status to children: to tell or not to tell. That is the question. Journal of Child and Family Studies, 16(6).

Tronto, J. C. (1993). Moral boundaries: A political argument for an ethic of care. Routledge.

Turan, J. M., Miller, S., Bukusi, E. A., Sande, J., \& Cohen, C. R. (2008). HIV/AIDS and maternity care in Kenya: how fears of stigma and discrimination affect uptake and provision of labor and delivery services. AIDS Care, 20(8), 938-945.

UNAIDS. (2004). Women and HIV/AIDS: Confronting the crisis. Geneva: UNAIDS, UNFPA, UNIFEM.

UNAIDS. (2007). AIDS epidemic update, December 2007. Geneva: UNAIDS.

UNAIDS. (2008). Report on the global HIV/AIDS epidemic 2008. Geneva: UNAIDS.
UNICEF, UNAIDS, \& WHO. (2007). Children and AIDS: A stocktaking report. Actions and progress during the first year of Unite for Children, Unite against AIDS. UNICEF.

UNPD. (2007). Human Development Report 2007/2008. UNPD.

Upton, R. L. (2003). "Women have no tribe": connecting carework, gender, and migration in an Era of HIV/AIDS in Botswana. Gender and Society, 17(2), 314-322.

Van Damme, W., Kober, K., \& Kegels, G. (2008). Scaling-up antiretroviral treatment in Southern African countries with human resource shortage: how will health systems adapt? Social Science \& Medicine, 66(10), 2108-2121.

Van Graan, A., Van der Walt, E., \& Watson, M. (2007). Community-based care of children with HIV in Potchefstroom, South Africa. African Journal of AIDS Research, 6(3), 305-313.

Vaz, L., Corneli, A., Dulyx, J., Rennie, S., Omba, S., Kitetele, F., et al. (2008). The process of HIV status disclosure to HIV-positive youth in Kinshasa, Democratic Republic of the Congo. AIDS Care, 20(7), 842-852.

WHO. (2006). Treat, train, retain. The AIDS and the healthcare workforce plan. Report on the consultation on AIDS and human resources for health. Geneva: WHO.

WHO, UNAIDS, \& UNICEF. (2008). Toward universal access. Scaling up priority HIV/ AIDS interventions in the health sector. Progress report 2008. Geneva: WHO.

Wiener, L., Mellins, C. A., Marhefka, S., \& Battles, H. B. (2007). Disclosure of an HIV diagnosis to children: history, current research, and future directions. Journal of Developmental and Behavioral Pediatrics, 28(2).

Wong, V., Macleod, I., Gilks, C., Higgins, D., \& Crowley, S. (2006). The lost children of universal access - issues in scaling-up HIV testing and counselling. Vulnerable Children and Youth Studies, 1(1), 44-55.

Zimet, G. D., Mays, R. M., Sturm, L. A., Ravert, A. A., Perkins, S. M., \& Juliar, B. E. (2005). Parental attitudes about sexually transmitted infection vaccination for their adolescent children. Archives of Pediatrics and Adolescent Medicine, 159(2), 132-137. 